\title{
Inmunohistoquímica en el diagnóstico de fiebre amarilla
}

\author{
ELENA MUÑOZ1 ${ }^{1}$ CECILIA MORÓN ${ }^{1}$, ROBERTO KEMPER ${ }^{2}$, RAÚL ROMÁN ${ }^{1}$ \\ ${ }^{1}$ Centro Nacional de Salud Pública. Instituto Nacional de Salud. Departamento de Patología. \\ ${ }^{2}$ Hospital Arzobispo Loayza, Departamento de Patología. Lima, Perú.
}

\begin{abstract}
Resumen
Obejivo: Confirmar la presencia del antígeno del virus de la fiebre amarilla en muestras de hígado. Material y Métodos: Se aplicó la técnica de inmunohistoquímica en muestras de hígado de 34 pacientes procedentes de las diferentes regiones del país con diagnóstico clínico de fiebre amarilla, durante los años 1999 a 2001. A los cortes de tejido (hígado parafinizado) se aplicó esta técnica con anticuerpos monoclonales y policlonales contra FA y el complejo biotina-streptavidina. El control positivo fue el hígado de un paciente con diagnóstico serológico e histopatológico de fiebre amarilla y el control negativo una muestra de hígado obtenida de la necropsia de un paciente con patología no hepática. Resultados: La positividad se dio por una tinción marrón en el citoplasma hepático. Las muestras negativas carecen de esta tinción. Se confirmó la presencia de antígeno de fiebre amarilla durante los años 1999 al 2001. Las 34 muestras procedieron de los departamentos de San Martín, Junín, Cuzco, Huánuco, Loreto, Pasco, y Ucayali. Conclusión: La técnica de inmunohistoquímica constituye una herramienta de diagnóstico por su alta sensibilidad y especificidad (ambas 90\%), para estudios epidemiológicos en los que se puede realizar un diagnóstico retrospectivo.
\end{abstract}

Palabras clave: Inmunohistoquímica; Fiebre amarilla; Tejidos; Antígeno.

\section{Immunohistochemistry in the diagnosis of yellow fever} Abstract

Objective: To determine the presence of yellow fever virus antigen in liver samples. Material and Methods: Immunohistochemistry assay was used in liver samples obtained from 34 patients from 1999 through 2002; they lived in different regions of the country and presented clinical diagnosis of yellow fever. Monoclonal and polyclonal antibodies against yellow fever virus and biotin-streptavidin complex were applied to liver sections (paraffinized-liver). A liver sample from a patient with serological and histophatological diagnosis of yellow fever was used as positive control and a negative control was a liver sample obtained at necropsy from a patient without liver disease. Results: Brown staining of the liver cell cytoplasm was considered positive. The presence of yellow fever virus antigen was confirmed in the 34 liver samples studied from 1999 to 2001. Patients came San Martín, Junín, Cuzco, Loreto, Pasco and Ucayali departments. Conclusion: Immunohistochemistry assay is a useful diagnostic tool for epidemiologic studies due to its high sensitivity and specificity (90\%), when a retrospective diagnosis may be performed.

Key words: Immunohistochemistry; Yellow fever; Tissues; Antigen.

\section{INTRODUCCIÓN}

La fiebre amarilla (FA) es una enfermedad infecciosa aguda que en su forma grave se caracteriza por un cuadro icterohemorrágico de corta duración (habitualmente menos de 10 días) y elevada mortalidad. Se presenta en forma epidémica y es causada por un virus ARN de la familia Flaviviridae. La enfermedad se presenta en dos formas epidemiológicas: la forma urbana y la forma selvática, clínica e histopatológicamente semejantes $\left(^{1}\right)$.

En 1995, se reportó en el país 440 casos, 
incluyendo 169 muertes, en un período de 6 meses. En 1999, se reportó 25 casos de FA por histopatología. El año 2000 hubo un total de 6 casos positivos diagnosticados por serología Mac Elisa y 3 por histopatología. El año 2001 se diagnosticó un total de 27 casos por serología y 4 casos positivos sólo por patología $\left({ }^{1}\right)$.

En nuestro país, la forma predominante de transmisión durante los últimos 50 años es la FA selvática. Las zonas que han notificado el mayor número de casos durante este período son los departamentos de San Martín, Junín, Cerro de Pasco, Huánuco, Apurímac, Ayacucho, Ucayali, Madre de Dios, Puno, Cuzco y Loreto $\left({ }^{2}\right)$.

En la actualidad, existen pruebas de laboratorio para el diagnóstico de FA, como son la serología, cultivo celular, histopatología, técnicas de biología molecular -como PCR a partir de tejidos fijados-y la inmunohistoquímica (IHQ). Esta técnica empezó a desarrollarse con Coons $\left({ }^{3}\right)$, quien añadió fluoresceína a las moléculas del anticuerpo y observó los cortes de los tejidos en el microscopio con luz ultravioleta. La IHQ identifica, mediante técnicas inmunológicas, el origen de las células, tejidos y agentes infecciosos en frotis o en cortes histológicos y se basa en la capacidad de los anticuerpos de unirse específicamente a los correspondientes antígenos; esta reacción es visible sólo si el anticuerpo está marcado con una sustancia que absorbe o emite luz o produce coloración $\left({ }^{3}\right)$. Las células producen proteínas que actúan como antígenos, los cuales aplicados a seres vivos (ratas, conejos, etc.) estimulan la producción de anticuerpos. La IHQ entonces es una técnica de inmunotinción que permite demostrar una variedad de antígenos presentes en las células o tejidos, utilizando anticuerpos marcados.

La limitación de esta tecnología se da en el tiempo que transcurre desde la toma de muestra (tejido) hasta la fijación del mismo, el cual no debe exceder de cuatro horas posmortem, para obtener cortes histológicos óptimos y así realizar un buen diagnóstico histopatológico e inmunohistoquímico. Cuando la muestra es tomada después de las horas indicadas, se produce la autólisis (cambios autolíticos por mala fijación) y eso hace imposible el diagnóstico.

Esta tecnología ha sido empleada con el objetivo de detectar histológicamente antígenos virales de FA evaluados previamente por histopatología, en tejidos de pacientes con sospecha de FA. Ello se justifica, ya que a pesar de los costos (elevados) es considerado como un procedimiento efectivo y en algunos casos indispensable. Con la histología con hematoxilina eosina no se logra visualizar este complejo antígeno- anticuerpo, porque son moléculas muy pequeñas e incoloras $\left({ }^{4}\right)$. Actualmente, se produce gran número de anticuerpos, con un alto grado de pureza (monoclonales), elevada sensibilidad (detectan anticuerpos aunque se encuentren en cantidades muy pequeñas) y especificidad (reconocen el antígeno que se busca con mínimas reacciones cruzadas), por ejemplo, en cortes de riñón, piel y en ganglios linfáticos, los cuales son utilizados en la IHQ $\left(^{5}\right)$.

\section{MATERIAL Y MÉTODOS}

Estudio descriptivo que incluyó 34 muestras de hígados (todas de pacientes fallecidos) procedentes de las diferentes regiones del país con sospecha clínica de FA, a las que se realizó un análisis Inmunohistoquímico para identificar antígeno (Ag) específico de fiebre amarilla. Estas muestras pertenecen al archivo del Departamento de Patología del Instituto Nacional de Salud.

Con relación al procedimiento de inmunohistoquímica, se realizó un diagnóstico histopatológico a las muestras de hígado previamente fijadas en formol al $10 \%$. Los cortes fueron colocados en el procesador automático de tejidos (tiempo de procesamiento 12 horas en cada baño) 
por 45 minutos en cada paso de: etanol $70 \%$ (2 pasos), etanol absoluto ( 2 pasos), xilol (3 pasos), parafina ( 2 pasos). Se obtuvo secciones (cortes) de $3-4 \mathrm{u}$ por medio de un micrótomo digital. Éstas fueron extendidas sobre láminas portaobjeto, coloreadas con hematoxilina-eosina y vistas al microscopio para el diagnóstico histopatológico respectivo. Para la técnica de IHQ, los cortes fueron extendidos sobre láminas silanizadas, que permite una mejor fijación de los tejidos a la lámina. Antes de comenzar el trabajo, los cortes fueron sometidos a los procesos siguientes: desparafinación -se efectuó colocando las láminas en estufa a $57^{\circ} \mathrm{C}$ por 10 minutos, xilol- en dos pasos para terminar de extraer el resto de parafina contenida en el tejido; y rehidratación, las láminas fueron sumergidas en etanol absoluto por 10 minutos ( 2 pasos) y en etanol al $90 \%$ por 10 minutos (2 pasos). Posteriormente, se lavó 3 veces con agua destilada y se aplicó solución de peróxido de hidrógeno al $30 \%$, que actúa bloqueando las peroxidasas endógenas. Se lavó en agua destilada y PBS (pH 7,2-7,4). Se colocó bloqueador de proteínas libres en suero (bloquea las proteínas inespecíficas presentes en el hígado), se decantó y sin lavar se colocó los anticuerpos. Se tuvo muestras por duplicado, una para anticuerpos policlonales (fluido ascítico de ratón) y otra para anticuerpos monoclonales. El anticuerpo policlonal fue estandarizado a una dilución de 1/600. El anticuerpo monoclonal fue estandarizado a una dilución de 1/5000. Se aplicó luego el sistema de detección de IHQ, formado por la inmunoglobulina antiratón-anticonejo biotinilada y el conjugado estreptavidinperoxidasa. Ambos reactivos detectan el antígeno presente en el tejido, reaccionando con el anticuerpo primario. Para que esta reacción fuera visualizada, se aplicó una gota de solución sustrato- cromógeno diaminobencidina líquida (DAB) y se usó como colorante de contraste la hematoxilina. Como control positivo se utilizó el hígado de un paciente con diagnóstico serológico e histopatológico de fiebre amarilla. Como control negativo se usó una muestra de hígado obtenido de la necropsia de un paciente con patología no hepática. Todo este procedimiento fue realizado en cámara húmeda. La positividad estuvo dada por algún grado de tinción marrón en el citoplasma de los hepatocitos, lo que fue contrastado con una coloración azul-morado por la hematoxilina usada como contraste.

\section{RESULTADOS}

La presencia de antígenos del virus de FA fue demostrada por algún grado de tinción color marrón en el citoplasma de los hepatocitos, en muestras de hígado de pacientes con diagnóstico clínico de esta enfermedad. Se obtuvo buen contraste entre el tejido y el colorante hematoxilina (Figura $1)$.

Durante 1999, en los 27 casos incluidos se confirmó la presencia de antígeno de FA por inmunohistoquímica $(47,3 \%)$. La población masculina fue de $88 \%$ (24/27), DE 26,9 98,9. En el 2000 se encontró 1/20 ( $5 \%)$, con una población masculina de $5 \%$ $(1 / 20)$; y en el 2001, fue de 6/20 (30\%), con una población masculina de $85 \%(6 / 7)$ y DE $32,3 \pm 11,2$. Los casos de FA por IHQ según procedencia son explicados en la Tabla 1.

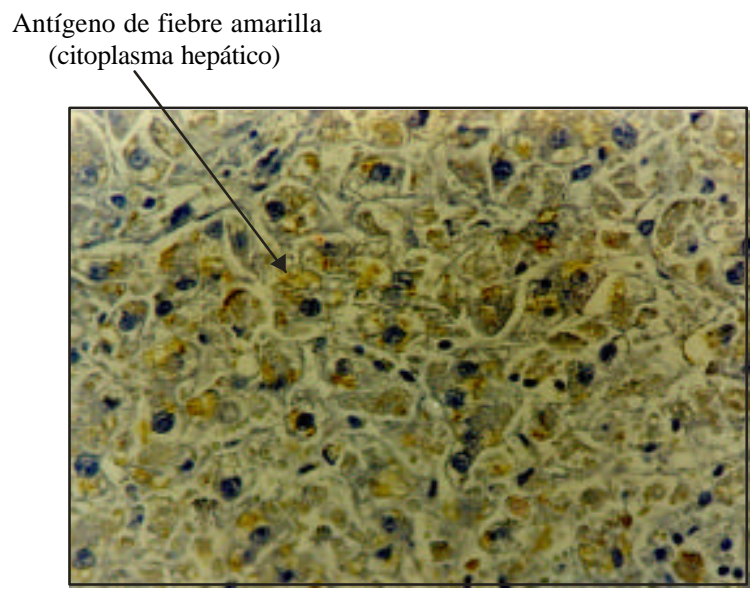

Figura 1. IHQ fiebre amarilla.

Tinción color marrón en el citoplasma de los hepatocitos. Método estreptavidin-peroxidasa (LSAB). 100X. 
Tabla 1. Casos de fiebre amarilla por IHQ según procedencia.

\begin{tabular}{lcccc}
\hline Procedencia & 1999 & 2000 & 2001 & Total \\
\hline San Martín & 9 & - & 4 & 13 \\
Ayacucho & 3 & - & - & 3 \\
Junín & 8 & - & - & 8 \\
Huánuco & 3 & - & 1 & 4 \\
Cuzco & 2 & 1 & - & 3 \\
Loreto & 1 & - & - & 1 \\
Pasco & 1 & - & - & 1 \\
Ucayali & - & - & 1 & 1 \\
\hline Total & 27 & 1 & 6 & 34
\end{tabular}

\section{DISCUSIÓN}

Las ventajas de la IHQ es que tiene utilidad diagnóstica en identificar la diferenciación de marcadores pronósticos de neoplasias (marcadores tumorales) $\left(^{6}\right)$, nos permite identificar el origen del tumor y en ocasiones podemos diferenciar entre hiperplasia benigna y neoplasia maligna (por ejemplo, en linfomas). También nos permite inferir sobre la respuesta al tratamiento, tiempo libre de recurrencia y el pronóstico (por ejemplo, en glándula mamaria). Además, existen anticuerpos que nos permiten reconocer en tejidos a parásitos (Pneumocystis carinii), virus (de hepatitis, papilomavirus, citomegalovirus, etc), bacterias (Helicobacter pylori) y otros.

Sus desventajas son falsos negativos por anticuerpo inadecuado, por estar caduco, degradado o por dilución inadecuada, pérdida de antígenos (por difusión o por necrosis del tejido, por lo que es importante el lapso entre la muerte del paciente y la toma de muestra), densidad menor del antígeno, esto en relación con la capacidad de detección (producción mínima o rápida liberación). Los resultados falsos positivos son más peligrosos y pueden deberse a: reactividad cruzada, unión inespecífica con el antígeno buscado, especialmente cuando se utiliza anticuerpos policlonales, presencia de peroxidasa endógena, atrapamiento de células normales entre células tumorales, liberación de proteínas solubles de células normales, las cuales pueden penetrar al intersticio y ser fagocitadas por macrófagos y por células tumorales $\left({ }^{7}\right)$. Por esta razón, se corrió conjuntamente controles negativos, que correspondían a una muestra de hígado obtenida en la necropsia de un paciente con patología no hepática.

Los diferentes ensayos de las técnicas inmunohistoquímicas que se realizaron permitieron hallar las diluciones óptimas de los anticuerpos y los tiempos de incubación más eficientes. La selección de parámetros adecuados se basó en la nitidez de las láminas, un resultado positivo bien definido y un contraste claro entre los positivos y los controles. Esta experiencia indica que el tiempo de incubación en cámara húmeda con el anticuerpo primario durante 10 minutos es suficiente para una buena unión de antígenos virales por parte de inmunoglobulinas policlonales $y$ monoclonales. Además, se determinó que la dilución del anticuerpo que permite una mayor inmunorreactividad positiva para esta tecnología es de 1/5000 para el anticuerpo monoclonal y 1/600 para el policlonal.

Nuestros resultados son satisfactorios y pueden ser comparados con los de otros autores, quienes han demostrado diferentes antígenos virales en tejidos. Así, están los resultados obtenidos por Hall y otros en la demostración de antígenos del dengue y del virus de fiebre amarilla en tejidos embebidos en parafina $\left.{ }^{8}\right)$. Otros autores han demostrado diferentes antígenos virales en tejidos, como los resultados obtenidos por Ricaurte y otros con fiebre amarilla $\left({ }^{9}\right)$, Sarmiento y otros, $\left({ }^{10}\right)$ Faran y otros en la detección de antígenos del virus de la fiebre del valle de Rift en secciones parafinadas de mosquitos transmisores $\left({ }^{11}\right)$; y en la determinación de los niveles séricos de $\operatorname{IgA}$ contra el antígeno de la cápside viral del virus Epstein-Barr $\left(^{12}\right)$. Muchos de estos autores utilizan diferentes variantes del método de la avidina-biotina como sistema amplificador de la reacción. 
También las técnicas estreptavidinabiotina han sido utilizadas en la detección de otros agentes no virales, como Mycoplasma pulmonis en tejidos parafinados, y han mostrado una alta sensibilidad $\left({ }^{13}\right)$. Incluso, Milios y Leong demostraron que la técnica avidinabiotina-peroxidasa puede detectar una gran variedad de antígenos en secciones histológicas estándar de tejidos normales previamente teñidos con hematoxilina y eosina, sin reducción detectable de la sensibilidad $\left({ }^{14}\right)$.

Cuando se requiere estudiar tejidos archivados por largo tiempo, es preferible utilizar los bloques de parafina, pues conservan los antígenos mejor que el tejido almacenado en formol. También se puede utilizar láminas con cortes teñidos previamente con hematoxilina eosina; al desteñirlos, no se afectan los epítopes $\left({ }^{15}\right)$.

También, se ha mejorado los fijadores de los tejidos para conservar los antígenos; sin embargo, sigue siendo útil el formol amortiguado al $10 \%$. Antes se pensaba que entre más tiempo estuvieran los tejidos en el formol se lograba una mejor fijación. Actualmente, se prefiere tiempos cortos ( 8 a 10 horas), ya que se sabe que las células pueden perder los antígenos por difusión. El fijador en ocasiones enmascara el sitio de la célula donde se manifiesta el antígeno (epitope). Para desenmascarar los epítopes, se ha desarrollado técnicas mediante el uso de enzimas o de calor. Entre éstas es común el uso de ollas de presión o el horno de microondas. Esta técnica requiere estandarización, precisión y estricto control de calidad. Un elemento importante a considerar es la óptima preservación del tejido (máximo 4 horas posmortem) y por ende de los antígenos. Éstos, en su mayoría se conservan adecuadamente después de la fijación en formalina e inclusión en parafina. Algunos son más lábiles y sólo son detectados en cortes de congelación. La mayoría de reactivos usados en IHQ son potencialmente carcinógenos y su manipulación debe ser cuidadosa.
De esta información se concluye que, la técnica de inmunohistoquímica constituye una de las herramientas útiles de diagnóstico específico por su gran valor diagnóstico, el cual también puede ser usado para la identificación de otras etiologías, como Leishmanias (Amastigotes en tejidos) hepatitis B, dengue, rickettsiosis (en células endoteliales), etc $\left({ }^{16}\right)$. Esta tecnología podría ser transferida a los laboratorios de referencia regionales, en donde se tenga implementada el área de Anatomía Patológica. Lamentablemente, esta implementación implica un costo elevado, a lo que se suma la escasez de patólogos en el interior del país.

Dada la situación epidemiológica que exhibe esta enfermedad, es necesario disponer de pruebas diagnósticas que permitan realizar oportunas medidas de control y prevención. Puesto que la letalidad de los pacientes con fiebre hemorrágica hospitalizados, puede ser de 30 a $80 \%\left({ }^{17}\right)$, hay casos en que el diagnóstico no puede hacerse mediante serología, por haberse producido la muerte del paciente y no disponerse del suero de convalecencia. A lo que se suma, a veces, el fracaso del aislamiento viral. En ellos, sólo queda la opción del diagnóstico retrospectivo, en el que las técnicas inmunohistoquímicas gozan de una gran aceptación $\left({ }^{18}\right)$.

\section{REFERENCIAS BIBLIOGRÁFICAS}

1. De Aristegui J, Corretger JM, García F, Hernandez T, Gonzalo CR. Manual de vacunas en pediatría. 1era ed. Madrid: Litofinter; 1997.

2. Neyra J. Sipan F. La fiebre amarilla, pasado y presente en el Perú. Rev Diag. 1983;12(03):86-95.

3. Taylor CR. Immunohistologic techniques in surgical pathology. A spectrum of «new» special steins. Hum Path. 1981;12:590-6.

4. Pelegrino JL, Arteaga E, Rodriguez AJ, Gonzales E, Frontera MC, Guzmán MG. Normalización de técnicas inmunohistoquímicas para la detección de antígenos del virus dengue en tejidos embebidos en parafina. Instituto de Medicina Tropical "Pedro Kourí". Rev Cub Med Trop. 1997;49(2):8693.

5. Taylor CR, Chir B, Phil D. Immunoperoxidase technics. Arch Pathol Med. 1978;102:113-21. 
6. Tetu B, Brisson J. Prognostic significance of HER- 2/neu oncoprotein expression in node positive breast cancer; the influence of the pattern of immunostaining and adjuvant therapy. Cancer. 1994;73:2359-65.

7. Drobnjak M, Cote RJ, Drudis T, Cordon C. p53 and Rb alterations in primary breast carcinoma: correlation with receptor expression and lymph node metastases. Intl J Oncol. 1993;2:173-8.

8. Toikkanen S, Helin H, Isola I, Joensuu A. Prognostic significance of HER-2 oncoprotein expression in breast cancer: a 30 year follow up. J Clin Oncol. 1992;10:1044-8.

9. Ricaurte O, Sarmiento L, Caldas ML, Rodríguez G, Altamar E. Evaluation of immunohistochemical method in yellow fever diagnosis. Informe del Grupo de Patologías. Bogotá: Instituto Nacional de Salud; 1992.

10. Sarmiento L, Rodríguez G, Boshell J. Diagnóstico immunohistoquímico del dengue en cortes de parafina. Biomed. 1995;15:10-5.

11. Faran ME, Romoser WS, Routier RG, Bailey ChL. Use of the avidin biotin- peroxidase complex immunocytochemical procedure for detection of Rift Valley fever virus in paraffin section of mosquitoes. Am J Trop Med Hyg. 1986; 35(5):1061-7.

12. Se Thoe SY, Sam CK, Cheng HM, Prasad U. Improved sensitivity of detection by avidin- biotin complex (ABC), immunocytochemistry in Epstein- Barr virus serology. J Med Virol. 1989;29:311-4.

13. Brunnert SR, Dai Y, Kohn DF. Comparison of polymerase chain reaction and immunohistochemistry for the detection of Mycoplasma pulmonis in paraffin- embedded tissue. Lab Anim Sc. 1994;44(3):257-60.

14. Milios J, Leong ASY. The application of the avidin- biotin technique to previousty stained histological sections. Stain Tech. 1987;62(6):411-6.

15. Muss HB, Thor AD, Berry DA, Kute T, Liu ET, Koerner F, et al. c-erbB-2 expression and response to adjuvant therapy in women with node positive early breast cancer. N Engl J Med. 1994;330:1260-6.

16. Bacchi CE, Grown AM, Bacchi MM. Detection of infectious disease agents in tissue by immunocytochemistry. Braz $\mathrm{J}$ Med Biol Res. 1994;27(12):2803-20.

17. Organización Panamericana de la Salud. Alternativas para la prevención y control del dengue y del dengue hemorrágico en los países de Centroamérica. Washington: OPS/OMS; 1995.

18. Nadji M, Morales AR. Immunoperoxidase techniques: a practical approach to tumor diagnosis. Chicago: American Society of Clinical Pathologist; 1986.

\section{Correspondencia:}

Tec.Méd. María Elena Muñoz Zambrano

Instituto Nacional de Salud. Calle Cápac Yupanqui 1400

Lima 11, Perú

Correo-e:mmunoz@ins.gob.pe 